\title{
Editorial - Vol. 1, Issue 1
}

\section{ANTIBIOTIC RESISTANCE}

\author{
Edwin Dias ${ }^{1}$, Meena Dias ${ }^{2}$, \& Deeksha N. Acharya $^{3}$ \\ ${ }^{1}$ Professor and HOD, Department of Paediatrics, SIMS \& RC, Mangalore, India \\ ${ }^{2}$ Associate Professor, Department of Microbiology, Fr Muller Medical College, India. \\ ${ }^{3}$ Intern, SIMS \& RC, Mangalore, India. \\ E-mail : dredwindias@gmail.com
}

Type of the Paper: Editorial.

Type of Review: Peer Reviewed.

Indexed In: OpenAIRE.

DOI: http://dx.doi.org/10.5281/zenodo.800689.

Google Scholar Citation: IJHSP

\section{How to Cite this Paper:}

Dias, Edwin., Dias, Meena., Acharya, Deeksha N. (2017). Antibiotic Resistance. International Journal of Health Sciences and Pharmacy (IJHSP), 1(1), E1-E3.

DOI: http://dx.doi.org/10.5281/zenodo.800689.

International Journal of Health Sciences and Pharmacy (IJHSP)

A Refereed International Journal of Srinivas University, India.

(C) With Authors.

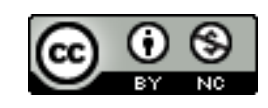

This work is licensed under a Creative Commons Attribution-Non Commercial 4.0 International License subject to proper citation to the publication source of the work.

Disclaimer: The scholarly papers as reviewed and published by the Srinivas Publications (S.P.), India are the views and opinions of their respective authors and are not the views or opinions of the SP. The SP disclaims of any harm or loss caused due to the published content to any party. 


\title{
Editorial - Vol. 1, Issue 1
}

\section{ANTIBIOTIC RESISTANCE}

\author{
Edwin Dias ${ }^{1}$, Meena Dias ${ }^{2}$, \& Deeksha N. Acharya ${ }^{3}$ \\ ${ }^{1}$ Professor and HOD, Department of Paediatrics, SIMS \& RC, Mangalore, India \\ ${ }^{2}$ Associate Professor, Department of Microbiology, Fr Muller Medical College, India. \\ ${ }^{3}$ Intern, SIMS \& RC, Mangalore, India. \\ E-mail : dredwindias@gmail.com
}

Bacterial resistance to antimicrobials is recognized by the WHO as a major health threat of the 21st century. Antimicrobial resistance threatens the effective prevention and treatment of an ever-increasing range of infections. Infections such as tuberculosis and septicaemia which decimated populations are once again responsible for mortality in epidemic proportions. Bacterial resistance is driven by the continued use of antimicrobials and it is unlikely that the danger of resistance can be effectively diminished by the discovery of new antimicrobials. The problem lies with the patent duration (20 years) and billion dollar investments of the pharmaceutical companies in producing a new antimicrobial. We have used, or are using, our so-called drugs of last resort. There is nothing left in the armamentarium and investments in developing new antimicrobials are missing, we are moving into the post-antimicrobial era.

The factors of poor public health systems and nosocomial infections along with high rates of infectious disease, inexpensive antibiotics and their over the counter availability, rising incomes has resulted in increase of prevalence of resistant pathogens in hospital setup. This lead to an increased burden on untreatable neonatal sepsis and health-care-associated infections. The antibiotic resistance crisis has been attributed to the overuse and misuse of these antimicrobial medications. Coordinated efforts to put forth new policies, renew research efforts, and taking efficient steps to manage the crisis are greatly needed.

Epidemiological studies have shown a direct relationship between antibiotic consumption and the emergence and dissemination of resistant bacteria strains. In bacteria, genes can be inherited from relatives or can be developed from nonrelatives on mobile genetic elements such as plasmids. This horizontal gene transfer (HGT) can allow antibiotic resistance to be transferred among different species of bacteria Resistance can also occur spontaneously through mutation [1]. Antibiotics are still being prescribed or sold for diarrheal diseases and upper respiratory infections for which they have not as much of value [2-3]. India's large population is an important factor contributing to the easy spread of resistant pathogens. Health system factors continue to be at fault. Infection control in hospitals is poorly monitored and could be improved. Over-the-counter access to antibiotics is a complex problem in India, but regulations have to be imposed to restrict access. These regulations have to be balanced against the need to maintain access, for the significant proportion of the population that lacks access to doctors.

Environmental antibiotic pollution increases the transfer of resistance genes to human commensal and pathogenic bacteria [4]. Specifically, waste water treatment plants serving antibiotic manufacturing facilities have been implicated in the transfer of resistance genes into human microbiota and are a serious threat to antibiotic effectiveness given the size of India's pharmaceutical sector [5].

In the developed and developing economies, antibiotics are widely used as growth supplements in livestock. Treating livestock with antimicrobials is said to improve the overall health of the animals, producing larger yields and a higher-quality product [6]. Recent studies in various regions of India have discovered antimicrobial residues in food animal products such as chicken meat and milk [7], indicating that antibiotic use in food animal production is widespread. This is one of the factors leading to antibiotic resistance as 
cited in UK. There are no standards for tolerance of antibiotic residues in poultry. Hence it's is ideal in making this important issue that has to be addressed urgently.

Poor public health indicators, rising incomes, and the availability of inexpensive antibiotics over the counter without a prescription are creating the ideal conditions for a large-scale dissemination of resistance genes in India. To decrease antibiotic resistance, efforts by groups like the Indian Association of Pediatrics, the Global Antibiotic Resistance Partnership [8], and the Chennai Declaration [9] have supported in building awareness about the problem among professional bodies, the media, policy makers, and the lay public. A high-level committee has been summoned to address the issue at the Ministry of Health and is expected to issue recommendations soon.

A few urgent priorities for immediate implementation are required. First, improved efficiency of drug regulatory bodies is essential to prevent powerful antibiotics being sold over the counter and to remove the use of antimicrobial growth promoters in livestock. Second, behaviour change is needed among physicians and patients. Educate the public and physicians in their prescription practice about the dangers of uncontrolled antibiotic use and their outcomes. Third, changes in rules under which physicians can accept compensation are already in place under the rules of the Medical Council of India, and should be extended to cover prescriptions for antibiotic sales. Fourth, there are very few data available on the extent of resistance, with the exception of a few single-hospital reports, despite the need for data in order to drive policy. A national surveillance platform is being built under Resistance Map (www.resistancemap.org), a global data repository for antimicrobial use and resistance, which depends on reports from accredited laboratory service providers ${ }^{(1)}$. The Indian Council of Medical Research has recognized a National Programme on Antimicrobial Surveillance in ten laboratories based at academic centres on priority pathogens identified by the World Health Organization. There is also a necessity for better surveillance data on antibiotic consumption as well as the magnitude of overuse. Fifth, India should remove antimicrobial growth promoters from livestock when these drugs are medically important and when these are premixed with feed. For examples the use of Colistin in cattle feed. Such regulations would have regional consequences and would send a strong signal of the country's commitment to tackle this issue.

\section{REFERENCES}

[1] Read AF, Woods RJ. Antibiotic resistance management. Evol Med Public Health. 2014; $1: 147$.

[2] (No authors listed ) The antibiotic alarm. Nature. 2013; 495:141.

[3] Piddock L J. The crisis of no new antibiotics-what is the way forward? Lancet Infect Dis. 2012; 12:249-253.

[4] Rutgersson C, Fick J, Marathe N, Kristiansson E, Janzon A, Angelin M, et al. Fluoroquinolones and qnr genes in sediment, water, soil, and human faecal flora in an environment polluted by manufacturing discharges. Environmental science \& technology. 2014; 48:7825-32.

[5] Johnning A, Moore E.R., Svensson-Stadler L., Shouche Y.S., Larsson D.G., Kristiansson E. Acquired genetic mechanisms of a multiresistant bacterium isolated from a treatment plant receiving wastewater from antibiotic production. Appl Environ Microbiol. 2013; 79:725663.

[6] Michael CA, Dominey-Howes D, Labbate $M$. The antibiotic resistance crisis: causes, consequences, and management. Front Public Health. 2014; 2:145.

[7] Kakkar M, Rogawski L. Antibiotic Use and Residues in Chicken Meat and Milk Samples from Karnataka and Punjab, India. New Delhi, India: Public Health Foundation of India, 2013.

[8] Gould IM, Bal AM. New antibiotic agents in the pipeline and how they can overcome microbial resistance. Virulence. 2013; 4:185 -191.

[9] Ghafur A. The Chennai Declaration: a solution to the antimicrobial resistance problem in the Indian subcontinent. Clin Infect Dis. 2013;56(8):1190. 